\title{
Maternal-neonatal transmission of Enterococcus strains during delivery
}

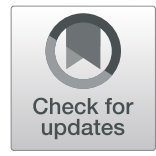

\author{
Ashlesha Bhagwat ${ }^{*}$ and Uday S. Annapure
}

\begin{abstract}
Background: Cesarean delivery (c-section) is on the rise globally. C-section is generally preferred if complications prevail in a vaginal delivery. Some private institutions conduct it unnecessarily for economic gains. This has led to a severe risk to a child's health. The neonate's gut microbiota has been observed to be influenced by the mode of delivery. Lactobacilli and other bacteria are very vital for developing healthy gut flora. An attempt has been made to investigate the passage of lactic acid bacteria to the infant via delivery. The vaginal swabs of the mothers and fresh meconium samples of the newborns post-delivery were examined for the presence of lactobacilli through culture techniques.

Results: The present investigation revealed that c-section-delivered infants lacked these bacteria in comparison with vaginally delivered infants. Biochemical tests and $16 \mathrm{~S}$ rRNA sequencing showed similarity with groups 1, 2, 3, and 5 of Enterococcus genus. Phylogenetic analysis revealed more than $98 \%$ similarity with several Enterococcus species. E. canintestini, E.rivorum, and E. dispar were transferred frequently from mother to infants born via vaginal delivery. The strains were submitted to the NCBI GenBank database under accession numbers KX830968-KX830982.

Conclusion: The study supports the hypothesis of maternal-neonatal transmission of bacteria during delivery and also possibilities of isolating newer strains for probiotic use.
\end{abstract}

Keywords: Delivery, Gut flora, Enterococcus transmission, Probiotic

\section{Background}

Women perceive cesarean delivery as a labor-free and safest mode of delivery. Cesarean delivery is an abdominal surgery that invites risks like surgical complications and admission to the neonatal intensive care unit. It is also more expensive as compared to vaginal delivery. In global statistical analysis, the cost of unnecessary csection amounted approximately to US $\$ 2.32$ billion and of needed c-section was around US\$432 million [1]. A woman with a primary cesarean has a $10 \%$ chance of vaginal birth for subsequent deliveries [2]. In the USA and most Western countries, women have the right to opt for the mode of delivery. In the USA, one in three women opts for c-section. The UK National Health Service has stated that the death rate of women in cesarean delivery was three times more as compared to vaginal delivery. In India, National Family and Health Survey has reported that the c-section rate increased from 10.6

\footnotetext{
* Correspondence: ashbhagwat88@gmail.com

Department of Food Engineering and Technology, Institute of Chemical Technology, Mumbai 400019, India
}

$\%$ in 2006 to $17.2 \%$ in 2017 [3]. There is an alarming difference between the c-sections conducted in public and private institutions. Private institutions conduct more csections than public institutions. There is a greater chance of unnecessary cesarean being conducted by private institutions for their economic motives [4]. This statistical analysis is of concern and has predisposed several risks to the development and health of the child. Some of these include neonatal depression due to general anesthesia, fetal injury during hysterectomy, respiratory distress, and breastfeeding complications. With the increasing trend of c-section, there has been an increase in the occurrences of autoimmune diseases like Crohn's disease, type 1 diabetes, multiple sclerosis, allergic diseases like asthma, rhinitis, and atopic dermatitis. These diseases have now been affluent in Western and industrialized countries [5].

The fetal gastrointestinal tract is considered to be sterile [6-8]. The colonization of microorganisms in the newborn begins during delivery and also within minutes after birth [9]. The establishing microorganisms originate from 
the vaginal and gastrointestinal flora of the mother, from environmental sources and consumption of breast milk along with formula milk. Different types of maternal vaginal bacteria come in contact with the mouth of the infant, and they act as an inoculum for the development of the gut flora. The intestinal microbiota of a newborn is highly dependent on the mode of delivery. The immune system undergoes a major development during infancy. This development is highly related to the colonization of the gut flora of the infant. It has been observed that vaginally delivered infants have a diverse microflora than c-sectiondelivered infants. $\mathrm{C}$-section was considered as a life-saving procedure during complex deliveries. The c-section delivery often contributes to prolonged mother-infant separation, longer hospital stays, and delayed or shorter breastfeeding periods [10]. This favors the outgrowth of unwanted, harmful, and pathogenic bacteria. These factors lead to delayed intestinal colonization of these infants. It has also been observed that the beneficial bacteria were not found in these infants until 6 months of birth. Moreover, women who undergo premature labor or c-section are exposed to a broad spectrum of antibiotic treatment. This, in turn, causes the reduction of useful intestinal microbiota [11].

Enterococci are commonly found on the first day of life and are among the first microorganisms detected in the stool of infants. Enterococcus genus accounts for up to $2 \%$ of the total vaginal flora. This family has been targeted for its probiotic properties. Enterococcus and Escherichia are the first to colonize the infant's gut flora and establish an anaerobic environment which, in turn, establish favorable conditions for the growth of Firmicutes and other useful bacteria $[12,13]$. The enterococci are present up to $10^{8} \mathrm{cfu} / \mathrm{g}$ in stool samples and constitute part of the normal human intestinal flora. These bacteria are also found in the human genital tract and oral cavity [14, 15]. Many strains of E. faecalis produce bacteriocins called enterocins, a family of safe [16] and ribosomally synthesized antimicrobial peptides that inhibit pathogenic organisms [17]. There are many factors known to influence the composition of the microbial flora in infants during and after birth $[1,2,4]$. Several researchers have observed that preterm infants and csection-delivered infants exhibited a delayed intestinal colonization along with a smaller number of species variability and a higher rate of potentially pathogenic microorganisms $[6,8,9,18]$. Treatment with antibiotics decreases the amount of anaerobic bacteria while increasing the number of Enterobacteriaceae in the infant's stool [9]. Pre-term births are likely predisposed to necrotizing enterocolitis (NEC) than term births [19]. However, interestingly, one study revealed that infants who developed NEC carried less E. faecalis [20]. A study relating to allergy development in infants during the first year of life showed that babies with allergies were less often colonized with Enterococcus during the first month of life when compared to healthy infants [21]. This implicates the importance of Enterococcus in intestinal immune development in earlier months of life. However, some reports have shown that they act as opportunistic pathogens, but their probiotic properties cannot be ignored [22]. Selection of avirulent enterococci from maternal source with probiotic properties would help in the reconstitution of the gut flora of c-section babies. Various non-culturable techniques have been adopted recently to study the organisms transferred during delivery [23].

In a previous study, we have already characterized the enterococci strains obtained from mother-infant transmission as potential probiotic candidates [24, 25]. The literature has reported very few studies on the vertical transmission of Enterococcus from mother to infant during delivery. In the present study, we investigate the transmission, isolation, and identification of enterococci during delivery.

\section{Methods}

\subsection{Sampling}

Thirty-five mother-infant pairs were enrolled in this study. Out of these, 23 women had vaginal delivery while 12 women underwent c-section. The women were explained the study and an informed consent was obtained from them. These women were healthy, in their reproductive age (20-35 years) with weight $40-70 \mathrm{~kg}$. Their diet consisted of cereals, legumes, vegetables, dairy products, and/or meat. They were not on antibiotics or any probiotic supplements. Cases including rupture of membranes or chorioamnionitis were excluded. Women with vaginal infections, vaginal hemorrhage, past history of any sexual diseases, HIV positive, or hepatitis B positive were excluded from the study. Also, women with smoking, alcoholism, and other such addictions were excluded from this study. The study was approved by Lokmanya Tilak Municipal Corporation General Hospital, Mumbai, India.

In this study, vaginal swabs of healthy pregnant women in their third trimester were obtained. The samples were collected randomly during 5 days prior to delivery. The vaginal lateral wall was swabbed, inoculated into Amies transport medium, stored in icepacks, and was transported to the lab within $2 \mathrm{~h}$. The samples were serially diluted in PBS ( $\mathrm{pH} 7)$ and plated on MannRogosa-Sharpe (MRS) agar plates followed by $48 \mathrm{~h}$ of anaerobic incubation at $37^{\circ} \mathrm{C}$. The first and fresh meconium samples of the neonates were obtained and immediately transported to the laboratory. One gram of sample was serially diluted up to $10^{8}$ using sterile PBS ( $\mathrm{pH}$ 7.0) and viable counts were carried out on MRS agar 
plates after incubating for $48 \mathrm{~h}$ at $37^{\circ} \mathrm{C}$ anaerobically. The colonies were characterized by Gram staining and a catalase test. Gram-positive and catalase-negative cocci were selected and inoculated in MRS broth with 30\% glycerol as cryo-protectant and stored at $-80^{\circ} \mathrm{C}$. All the protocols were carried out in duplicates [26].

\subsection{Biochemical characterization}

The strains obtained were screened for their physiological, morphological, and biochemical characteristics as described in Bergey's Manual of Systematic Bacteriology. The colonies were examined by Gram staining and for catalase production. The strains that were Gram-positive cocci and catalase-negative were further studied for their biochemical characteristics. The strains were screened for their sugar fermenting abilities using various sugars discs in peptone water. Sugars like arabinose, cellobiose, sorbitol, mannitol, mannose, lactose, maltose, glucose, melibiose, raffinose, ribose, salicin, rhamnose, sorbitol, xylose, tagatose, and trehalose at a final concentration of $1 \%$ were used for the study.

The strains were observed for temperature tolerance by growing in MRS broth at $4{ }^{\circ} \mathrm{C}, 15^{\circ} \mathrm{C}$, and $45^{\circ} \mathrm{C}$. Tolerance at $6 \% \mathrm{NaCl}$ and $3 \%$ bile concentration was carried out. Growth on potassium tellurite agar and sodium azide was carried out. The strains were also screened for ammonia production from arginine.

\subsection{Molecular identification of the strains}

After biochemical characterization, 15 representative strains from each group were selected for further molecular identification by $16 \mathrm{~S}$ rRNA sequencing. Genomic DNA was isolated from the culture by using Sigma's Gene Elute Bacterial Genomic DNA Kit. Around 600 bp of $\mathrm{V}_{3}-\mathrm{V}_{5}$ hypervariable region was amplified using the following combination of primers - FDD2 - RPP2 (universal primers for $1.5 \mathrm{kB}$ fragment amplification for eubacteria) Template DNA - Genomic DNA. Sequences of the primer pair used for amplification were

RPP2 - CCAAGCTTCTAGACGGITACCTTGTTAC GACTT, FDD2-CCGGATCCGTCGACAGAGTTTGAT CITGGCTCAG

The PCR products obtained from above reactions were then processed for cycle sequencing reaction using an Eppendorf Gradient Mastercycler system with a cycle of $94{ }^{\circ} \mathrm{C}$ for $5 \mathrm{~min}, 30$ cycles of $94{ }^{\circ} \mathrm{C}$, and $60^{\circ} \mathrm{C}$ and $72^{\circ} \mathrm{C}$ for $10 \mathrm{~min}$. The mixture was then held at $4{ }^{\circ} \mathrm{C}$. The PCR product was precipitated using polyethylene glycol (PEG $6000,8.5 \%)$, washed thrice using $70 \%$ ethanol, and then was dissolved in Tris- $\mathrm{HCl}(10 \mathrm{mM}, \mathrm{pH} 8.0)$. Following the above reaction, the samples were cleaned up and loaded on the sequencer Avant 3100 Gene Analyzer. The sequence output was compared with type strain $E n$ terococcus faecium ATCC 19454 in the EzTaxon database of the National Center for Biotechnology Information GenBank entries by using BLAST algorithm [27].

The phylogenetic tree was created with Mega 7 software using the neighbor-joining method. The sample sequences and affiliated known sequences from public databases were aligned, checked, and corrected using the Clustal W program in BioEdit. The evolutionary tree was inferred by bootstrapping 1000 replicates. The evolutionary distances were compared using the Maximum Composite Likelihood method and are in the units of the number of transversional substitutions per site. The differences in the composition bias among sequences were considered in evolutionary comparisons. The analysis consisted of 15 test nucleotide sequences. For comparison, 22 nucleotide sequences were procured from the GenBank database. All ambiguous positions were removed from each pair. There were total 1533 positions in the final dataset. Bootstrap values above $50 \%$ were displayed as percentages.

\section{Results}

\subsection{Sampling}

The viable counts of mother-infant pairs were calculated. The vaginally delivered babies showed good bacterial counts. The c-section-delivered babies showed no bacterial counts in their feces. Table 1 shows the number of species passed in the mother-infant pairs. Out of 23 vaginally delivered infants, 21 neonates shared at least one species from the mother. Enterococcus canintestini, Enterococcus dispar, and Enterococcus rivorum showed higher transmission among the pairs.

\subsection{Biochemical characterization}

Around 78 strains were selected from mother-infant pairs. The Gram-positive cocci were co-cultured and purified for biochemical studies. The strains were checked for their distinguishing fermentation abilities. Table 2 shows the biochemical characterization according to Bergey's Manual Of Systematic Bacteriology.

\subsection{Molecular characterization}

After the preliminary biochemical characterization, 15 strains were selected as representatives of each group and characterized by $16 \mathrm{~S}$ rRNA amplification and sequencing. The strains showed similarity to several species of the genus Enterococcus. The strains were compared with type strain Enterococcus faecium ATCC 19434. All the strains showed $98-100 \%$ similarity with the type strain. The species determination was carried out considering both phenetic characteristics and the sequence similarity with affiliated strains in the database. Figure 1 shows the phylogenetic tree constructed by neighbor-joining method. Strain SB2 shows $99.86 \%$ similarity with E. villorum; strains $\mathrm{AB} 3$ and S26B show 
Table 1 Comparison of bacterial counts in mother-infant pair and species shared during delivery

\begin{tabular}{|c|c|c|c|c|c|c|c|c|c|c|c|c|}
\hline \multirow{2}{*}{$\begin{array}{l}\text { Mother- } \\
\text { infant pair }\end{array}$} & \multirow{2}{*}{$\begin{array}{l}\text { Viable counts } \\
\log _{10} \text { mother }\end{array}$} & \multicolumn{2}{|c|}{ Viable counts $\log _{10} \mathrm{cfu} / \mathrm{ml}$ infants } & \multicolumn{9}{|c|}{ Bacterial species shared by the pair } \\
\hline & & VD & $C D$ & E. riv & E. dis & E.can & E. phe & E. vil & E. ita & E. rat & E.viik & E. tha \\
\hline 1 & $5.67 \pm 0.1$ & & ND & & $+/-$ & $+/-$ & & & & & & \\
\hline 2 & $5.95 \pm 0.07$ & $2.34 \pm 0.07$ & & & & $+/+$ & $+/+$ & $-/+$ & & & & \\
\hline 3 & $5.85 \pm 0.12$ & $2.28 \pm 0.13$ & & $-/+$ & & $+/+$ & & & & $+/+$ & & \\
\hline 4 & $4.68 \pm 0.03$ & & ND & & & $+/-$ & & & & & & \\
\hline 5 & $6.078 \pm 0.31$ & $3.56 \pm 0.15$ & & & & & & & & & & $+/+$ \\
\hline 6 & $6.15 \pm 0.41$ & $2.68 \pm 0.06$ & & $+/-$ & & & & & & & & \\
\hline 7 & $6.20 \pm 0.27$ & $2.43 \pm 0.14$ & & & & $-/+$ & & & & & & \\
\hline 8 & $5.78 \pm 0.07$ & $3.21 \pm 0.27$ & & & & & & & & & $+/-$ & \\
\hline 9 & $5.85 \pm 0.07$ & & ND & & & $+/+$ & & & & & & \\
\hline 10 & $5.43 \pm 0.15$ & $3.06 \pm 0.38$ & & & & & & & & $+/+$ & & \\
\hline 11 & $4.48 \pm 0.06$ & $3.24 \pm 0.21$ & & & & & & $+/+$ & & & & \\
\hline 12 & $5.30 \pm 0.02$ & & ND & & $+/-$ & & & & & & & \\
\hline 13 & $4.78 \pm 0.12$ & & ND & & & $+/-$ & & & & & & \\
\hline 14 & $5.77 \pm 0.04$ & & ND & $+/-$ & & $+/-$ & & & & & & \\
\hline 15 & $5.65 \pm 0.04$ & $3.36 \pm 0.19$ & & & & & $+/+$ & & & & & $-/+$ \\
\hline 16 & $5.67 \pm 0.45$ & $3.45 \pm 0.21$ & & $+/+$ & $+/+$ & & & & & & & \\
\hline 17 & $5.32 \pm 0.33$ & $3.76 \pm 0.16$ & & & & & & & $+/+$ & & $+/+$ & \\
\hline 18 & $4.98 \pm 0.52$ & $3.56 \pm 0.27$ & & & & $+/+$ & & & & & & \\
\hline 19 & $6.31 \pm 0.41$ & $3.77 \pm 0.19$ & & $+/+$ & & & & & & & & \\
\hline 20 & $5.54 \pm 0.26$ & & ND & & $+/-$ & & $+/-$ & & & & & $+/-$ \\
\hline 21 & $6.89 \pm 0.23$ & $2.94 \pm 0.09$ & & & & & & $+/+$ & & & & \\
\hline 22 & $5.95 \pm 0.34$ & $3.25 \pm 0.14$ & & $+/+$ & & & & & & & & \\
\hline 23 & $4.80 \pm 0.08$ & $3.66 \pm 0.23$ & & & & $+/+$ & & & $-/+$ & & & \\
\hline 24 & $5.76 \pm 0.02$ & & ND & $+/-$ & & & & & & & & \\
\hline 25 & $5.38 \pm 0.24$ & $2.98 \pm 0.33$ & & & $+/+$ & & & & & & & \\
\hline 26 & $5.81 \pm 0.01$ & & ND & & $+/-$ & $+/-$ & & & & & & \\
\hline 27 & $6.02 \pm 0.03$ & $3.44 \pm 0.21$ & & & $+/+$ & $+/+$ & & & & & & \\
\hline 28 & $6.45 \pm 0.09$ & $2.95 \pm 0.05$ & & $-/+$ & & $+/+$ & & & & & & \\
\hline 29 & $5.20 \pm 0.01$ & & ND & $+/+$ & & & & & & & & \\
\hline 30 & $6.91 \pm 0.37$ & $2.48 \pm 0.35$ & & $+/+$ & & $-/+$ & & & & & $+/+$ & \\
\hline 31 & $6.11 \pm 0.46$ & $3.16 \pm 0.11$ & & & & & & & & & & $+/+$ \\
\hline 32 & $5.97 \pm 0.48$ & & ND & & & & & & $+/-$ & & & \\
\hline 33 & $5.54 \pm 0.43$ & $2.79 \pm 0.26$ & & & & $+/+$ & & & & & & \\
\hline 34 & $6.70 \pm 0.36$ & $3.24 \pm 0.13$ & & $+/+$ & & & $+/+$ & & & & & \\
\hline 35 & $4.78 \pm 0.05$ & $3.67 \pm 0.17$ & & & $+/-$ & & & & & & & \\
\hline
\end{tabular}

Legend: Values are mean $\log _{10} \mathrm{cfu} / \mathrm{mL}$ (vaginal fluid) or $\log _{10} \mathrm{cfu} / \mathrm{g}$ (feces) \pm standard deviation

E. riv, Entercoccus rivorum; E. dis, Enterococcus dispar; E. can, Enterococcus canintestinii; E. phe, Enterococcus pheoniculicola; E. vil, E villorum; E. ita, Enterococcus italicus; E. rat, Enterococcus ratti; E. viik, Enterococcus viikiensis; E. thai, Enterococcus thailandicus; VD, vaginal delivery; $C D$, cesarean delivery; $N$, number of bacterial species shared by the pair; $+/+$, bacterial species was present in both the both mother and infant sample; $+/-$, bacterial species was present in the mother but absent in the infant; $-/+$, bacterial species absent in mother but present in infant; $N D$, not detected

98.56\% and $99.65 \%$ with E. canintestini; and strains S20A and S2 show $99.84 \%$ and $98.51 \%$ similarity with $E$. pheoniculicola, respectively. Strains S16 and S22C show 99.37\% and $99.53 \%$ similarity with E. rivorum, respectively. On the other hand, strains S10C, S16B, S27B,
S17B, and S3B show similarity with E. ratti (99.86\%), E. dispar (98\%, 98.78\%), E viikkiensis (99.56\%) and E. ratti (99.26\%), respectively. These strains were biochemically similar to the reported biochemical characteristics of the same species [28]. Seventy-eight strains were classified 


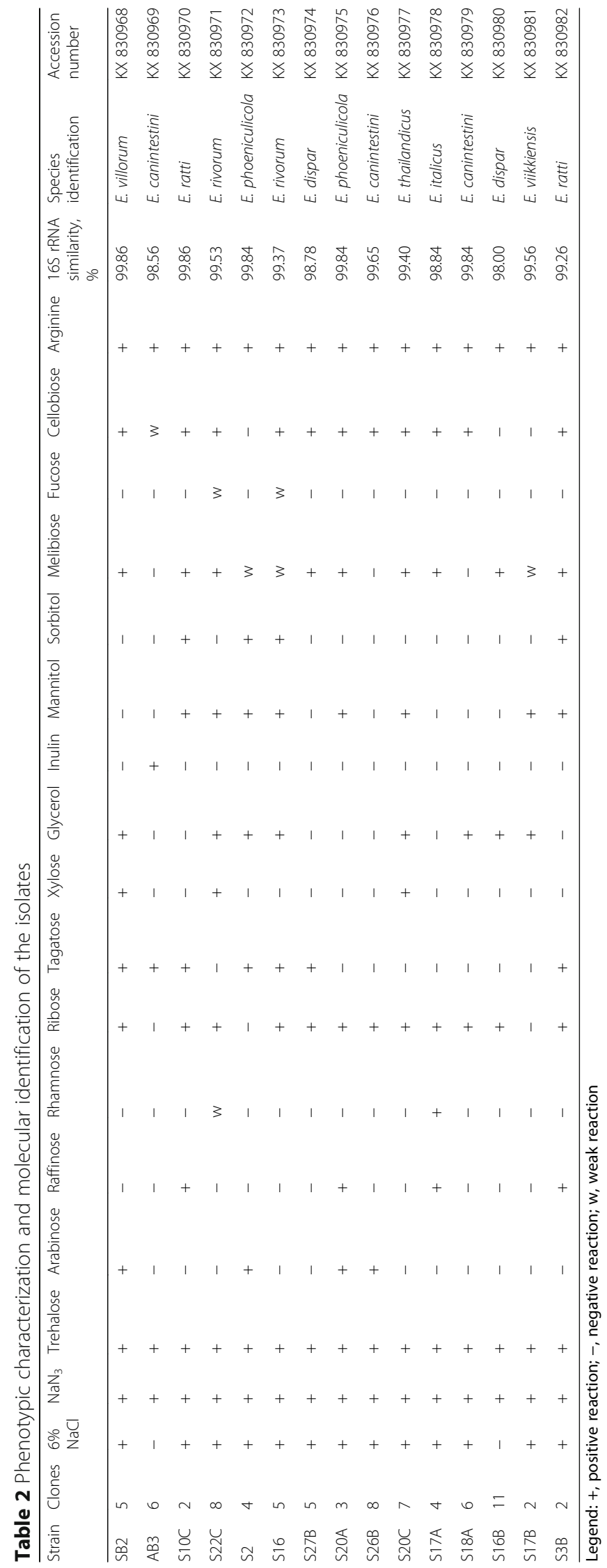




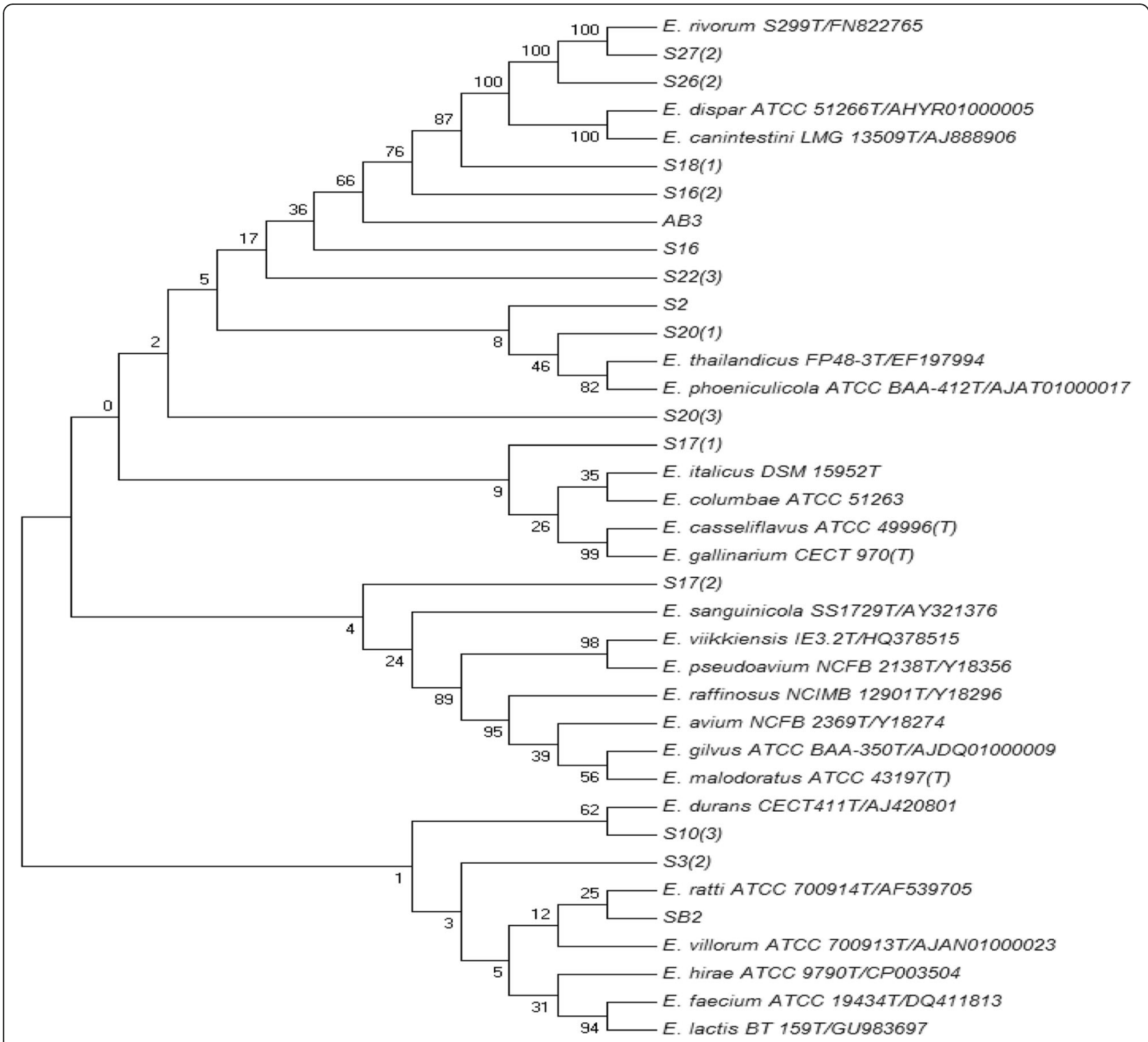

Fig. 1 Phylogenetic tree based on comparative analysis of $165 \mathrm{rDNA}$ sequences showing relationship among isolates and other enterococcal species

as $26 \%$ E. canintestini, $20 \%$ E. dispar, $17 \%$ E. riovrum, 9\% E. pheoniculicola, 9\% E. thailandicus, $6 \%$ E. villorum, $5 \%$ E. ratti, $5 \%$ E. itlaicus, and $3 \%$ E. viikkiensis. Enterococcus canintestini was the predominant strain. Similar results were observed by Belma et al. while profiling the presence of Lactobacillus species in the vagina [29]. Figure 2 shows the percentage of transmission of Entercoccus species in the mother-infant pairs. E. canintestini, E.rivorum, and $E$. dispar were transferred frequently within the pairs. All the strain sequences were submitted to the NCBI GenBank Database under accession numbers from KX830968-KX830982.

\section{Discussion}

The 16S rRNA sequencing showed that strains belong to groups 1, 2, 3, and 5 of Enterococcus genus. The identification of species of this genus is quite tedious. Generally for such strains having matches with distance scores > $0.5 \%$ next to the closest species, biochemical and other distinguishing properties hold importance in species identification. Hence, in this study, the identification was done by considering both biochemical characteristics and sequencing results $[30,31]$. The comparison of sequences shows $98-100 \%$ similarity with the type strain Enterococcus faecium ATCC 19454. The enterococci 


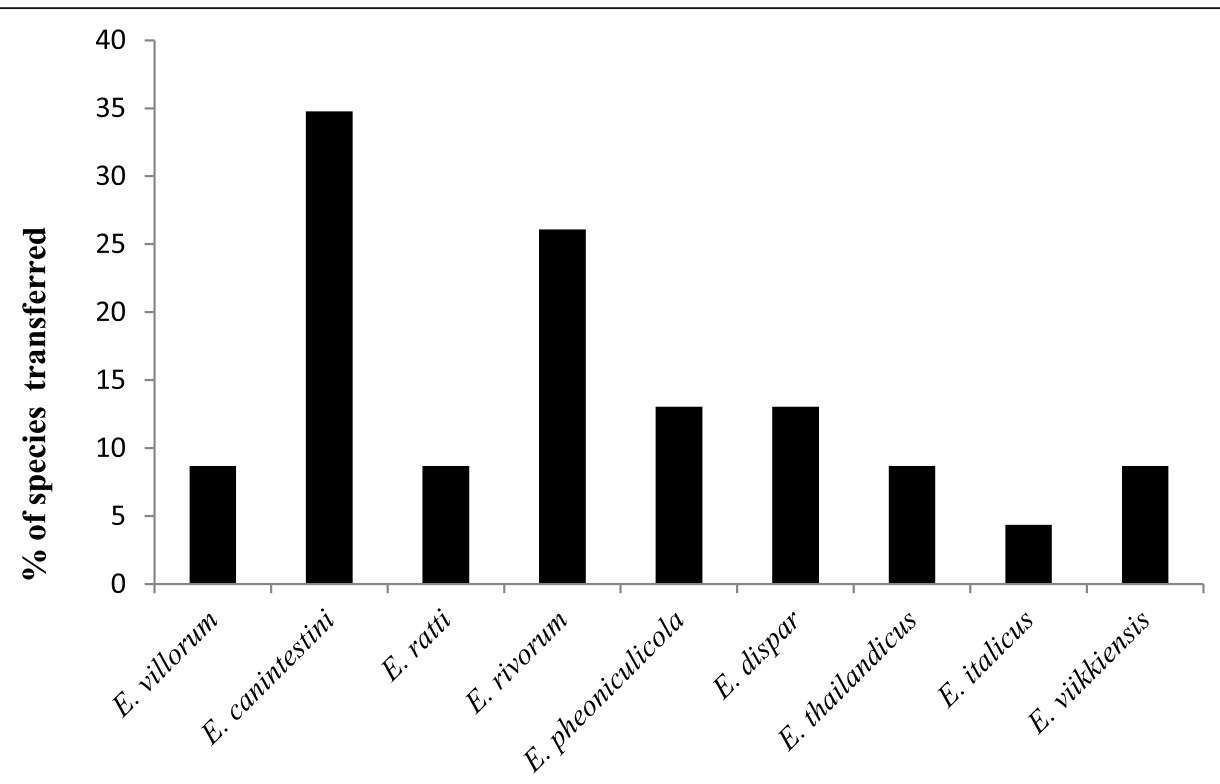

Fig. 2 Percentage distribution of Enterococcus species transferred to the infant during vaginal delivery

showed distinguishing fermentation abilities of mannitol, sorbitol, rhamnose, raffinose, arabinose, tagatose, etc. Table 2 shows the enterococci classification based on their sugar fermentation abilities and 16S rRNA sequencing results.

Many of the strains in this study were recently discovered like E. rivorum, E. canintestini, E. viikkiensis, and E. thailandicus from various sources [28, 32, 33]. E. rivorum was first reported in 2012 from the water source Brooks in Finland which was free from human inhabitation and hence ruled out human feces contamination [34]. E. canintestini was first reported in dog feces [35]. This study shows that these species are now widely spread in the human community too. Enterococcus thailandicus was first isolated from a fermented sausage in Thailand. It is closely related to E. hirae, E. durans, and E. faecium [36]. E. pheonicuicola was first isolated in 2003 from the uropygial gland of the Red-billed Woodhoopoe, Pheoniculus purpureus [32].

Figure 2 shows the comparison of the transfer of strains in mother-infant pair with monophyletic transmission. Monophyletic strains are species that are closely related to each other. In most of the vaginally delivered infants, it was observed that similar species were shared by the mother-infant pair. In contrast, c-section delivered infants did not show any transmission. Our findings confirm with earlier understanding that vaginal delivery aids in the transmission of mother's microbiota to the infant. Bacteria can induce a phenomenon called oral tolerance. Oral tolerance is created by the immune system against bacteria transferred orally or ingested. This tolerance helps in reducing over-reactive responses involved in allergies and auto-immune diseases. This study was based on the culture cultivation technique and was focused on specific genera. Hence, these results confirm that vaginal delivery facilitates the mother-infant transmission of enterococci [37]. As monophyletic strains were not observed in infants delivered by c-section, it confirms that monophyletic strains must have been transmitted through the birth canal during vaginal delivery [38]. Similar results were observed while profiling Bifidobacteria bacteria during delivery. In Finland, Gronlund et al. studied the transfer of Bifidobacteria in 61 mother-infant pairs. These women were supplemented with Bifidobacterium lactis and Lactobacillus GG until delivery [11]. Chen et al. conducted a similar study with 20 infants vaginally delivered and 20 by csection. He observed that the mean levels of bifidobacteria were significantly higher in vaginally delivered as compared to c-section infants [39]. Pender et al. also showed that cesarean delivery decreased the counts of bifidobacteria in the gut [40].

The human gut harbor a diverse microflora of numerous genera, species, and bacteria. This early colonization of the beneficial gut flora has an impact on the health of the child. It is highly related to the type of delivery, gestational period, and feeding habitat of the mother [41]. Several studies have confirmed the passage of the gut flora in the mother-infant pairs. These studies have proved that lactic acid bacteria induce a mucosal and humoral immune response. Wild-type lactoflora derived from human origin can be used as probiotics for treating diarrhea and allergies in children. Enterococcus faecium strains like SF68, EE3, and M-74 have been tested in animal feeds and they have proved their probiotic efficacy [22, 42]. One study has reported the role of E. faecalis, 
isolated from newborns, in infant gut protection. E. faecalis suppressed pathogen-mediated inflammatory responses in human IECs as well as DSS-induced inflammation in mice model. E. faecalis attenuated proinflammatory cytokine secretions, especially IL-8, via distinct pathways [13]. This confirms the role of colonizing bacteria in the postembryonic development of the gastrointestinal tract. The postembryonic maturation process is regulated by the commensal bacteria by crosstalking with host cells by recognizing receptors thereby inducing signaling pathways to activate transcription factors like nuclear receptors [43]. Another study has revealed that $E$. faecalis from newborn babies regulate endogenous PPARY activity and IL-10 levels in colonic epithelial cells [43]. Franz et al. showed that E. faecalis and E. faecium are involved in the reduction or prevention of gastrointestinal tract infections [44]. Studies involving Enterococcus strains isolated from the meconium of newborn infants have proved their potential for probiotic use $[24,45]$.

\section{Conclusion}

Gut microbiota of the neonate plays a crucial role in developing the infant's immunity. The present study confirmed that the mode of delivery plays an important role in the transmission of the gut microbiota at the time of birth. The comparison of bacterial counts of the motherinfant pair confirms that vaginal delivery is responsible for the natural inoculation of the gut of the infant. The study was solely dependent on culturing method and further research may include molecular techniques to investigate the footprint of the exact microbiome. However, the study built a strong foundation for developing a probiotic of vaginal strains from pregnant women for neonates born by cesarean delivery. The development of a probiotic formula might help reconstitute the gut microbiotia of c-section-delivered infants. Hence, further research will include a selection of potential probiotic organisms to develop a formula containing probiotic organisms.

\section{Abbreviations \\ BLAST: Basic local alignment search tool; DNA: Deoxyribose nucleic acid; MRS: Mann-Rogosa-Sharpe; NaCl: Sodium hydrochloride; PBS: Phosphate- buffered saline; PCR: Polymerase chain reaction; PEG: Polyethylene glycol; RNA: Ribose nucleic acid; Tris-HCl: Tris (hydroxymethyl) aminomethane (THAM) hydrochloride}

\section{Acknowledgements}

We would like to thank the Department of Obstetrics and Gynecology, Lokmanya Tilak Municipal Corporation General Hospital, Mumbai, India, for providing samples required for the project.

\section{Authors' contributions}

AB performed the experiments and wrote the manuscript. USA supervised the work and edited the manuscript. To this end, both authors have read and approved the final manuscript for publication.

\section{Funding}

This work was funded by University Grants Commission-Basic Science Research (UGC-BSR), India. The funds were used to buy media and chemicals required for the project.

\section{Availability of data and materials}

Not applicable

\section{Ethics approval and consent to participate}

The study was approved by the Ethics Committee of Lokmanya Tilak General Municipal Corporation Hospital, Mumbai, India, with reference no. IEC/04/13. A written and informed consent was obtained from all the subjects.

\section{Consent for publication \\ Not applicable}

\section{Competing interests}

The authors declare that they have no competing interest.

Received: 4 November 2019 Accepted: 11 December 2019

Published online: 21 December 2019

\section{References}

1. Gibbons L, Belizán JM, Lauer JA (2010) The global numbers and costs of additionally needed and unnecessary caesarean sections performed per year: overuse as a barrier to universal coverage. World Heal Rep Backgr Pap: $1-31$

2. Osterman MJK, Martin JA (2014) National vital statistics reports primary cesarean delivery rates, by state: results from the revised birth certificate, $2006-2012$, p 63

3. Nazneen R, Begum R, Sultana K (1970) Rising trend of caesarean section in a tertiary hospital over a decade. J Bangladesh Coll Physicians Surg. https:// doi.org/10.3329/jbcps.v29i3.9432

4. A TR. Increasing trend of caesarean rates in India: evidence from NFHS-4. J Med Sci Clin Res 2017;5:26167-26176. doi: https://doi.org/10.18535/jmscr/ v5i8.31.

5. Gosalbes MJ, Llop S, Moya A (2013) Meconium microbiota types dominated by lactic acid or enteric bacteria are differentially associated with maternal eczema and respiratory problems in infants. Clin Exp Allergy 43:198-211. https://doi.org/10.1111/cea.12063

6. Fanaro S, Chierici R, Guerrini P, Vigi V (2003) Intestinal microflora in early infancy: composition and development, pp 48-55

7. Mackie Rl, Sghir A, Gaskins HR (1999) Developmental microbial ecology of the neonatal gastrointestinal tract. Am J Clin Nutr. https://doi.org/10.1093/ ajcn/69.5.1035s

8. Schwiertz A, Gruhl B, Löbnitz M, Michel P, Radke M, Blaut M (2003) Development of the intestinal bacterial composition in hospitalized preterm infants in comparison with breast-fed, full-term infants. Pediatr Res. https:// doi.org/10.1203/01.PDR.0000078274.74607.7A

9. Orrhage K, Nord CE (1999) Factors controlling the bacterial colonization of the intestine in breastfed infants. Acta Paediatr Int J Paediatr Suppl. https:// doi.org/10.1111/j.1651-2227.1999.tb01300.x

10. Hobbs AJ, Mannion CA, McDonald SW, Brockway M, Tough SC (2016) The impact of caesarean section on breastfeeding initiation, duration and difficulties in the first four months postpartum. BMC Pregnancy Childbirth. https://doi.org/10.1186/s12884-016-0876-1

11. Grönlund MM, Grzeskowiak $Ł$, Isolauri E, Salminen S (2011) Influence of mother's intestinal microbiota on gut colonization in the infant. Gut Microbes 2:226-233. https://doi.org/10.4161/gmic.2.4.16799

12. Houghteling PD, Walker WA (2015) Why is initial bacterial colonization of the intestine important to infants' and children's health? J Pediatr Gastroenterol Nutr. https://doi.org/10.1097/MPG.0000000000000597

13. Wang S, Hibberd ML, Pettersson S, Lee YK (2014) Enterococcus faecalis from healthy infants modulates inflammation through MAPK signaling pathways. PLoS One. https://doi.org/10.1371/journal.pone.0097523

14. Huycke MM, Sahm DF, Gilmore MS (1998) Multiple-drug resistant enterococci: the nature of the problem and an agenda for the future. Emerg Infect Dis. https://doi.org/10.3201/eid0402.980211

15. Noble CJ (1978) Carriage of group D streptococci in the human bowel. J Clin Pathol. https://doi.org/10.1136/jcp.31.12.1182 
16. Belguesmia $Y$, Madi A, Sperandio D, Merieau A, Feuilloley M, Prévost $H$ et al (2011) Growing insights into the safety of bacteriocins: the case of enterocin S37. Res Microbiol. https://doi.org/10.1016/j.resmic.2010.09.019

17. Drider D, Rebuffat S (2011) Prokaryotic antimicrobial peptides: from genes to applications. https://doi.org/10.1007/978-1-4419-7692-5_1

18. Gewolb IH, Schwalbe RS, Taciak VL, Harrison TS, Panigrahi P (1999) Stool microflora in extremely low birthweight infants. Arch Dis Child Fetal Neonatal Ed. https://doi.org/10.1136/fn.80.3.F167

19. Hufnagel $M$, Liese $C$, Loescher $C$, Kunze $M$, Proempeler $H$, Berner $R$ et al (2007) Enterococcal colonization of infants in a neonatal intensive care unit: associated predictors, risk factors and seasonal patterns. BMC Infect Dis 7: 107. https://doi.org/10.1186/1471-2334-7-107

20. Normann E, Fahlén A, Engstrand L, Lilja HE (2013) Intestinal microbial profiles in extremely preterm infants with and without necrotizing enterocolitis. Acta Paediatr Int J Paediatr. https://doi.org/10.1111/apa.12059

21. Björkstén B, Sepp E, Julge K, Voor T, Mikelsaar M (2001) Allergy development and the intestinal microflora during the first year of life. J Allergy Clin Immunol. https://doi.org/10.1067/mai.2001.118130

22. Araújo TF, Lúcia C, Fortes DL (2013) The genus enterococcus as probiotic: safety concerns. 56:457-466

23. Pandey PK, Siddharth J, Verma P, Bavdekar A, Patole MS, Shouche YS et al (2012) Brief communication molecular typing of fecal eukaryotic microbiota of human infants and their respective mothers. J Biosci 37:221-226. https:// doi.org/10.1007/s12038-012-9197-3

24. Bhagwat A, Nandanwar YS, Warke R, Annapure US (2019) In vitro assessment of physiological properties of enterococcus strains of human origin for possible probiotic use. Asian J Pharm Clin Res 12

25. Bhagwat A, Annapure US (2019) In vitro assessment of metabolic profile of Enterococcus strains of human origin. J Genet Eng Biotechnol 17:11. https:// doi.org/10.1186/s43141-019-0009-0

26. Pascual LM, Daniele B, Pa C, T LB. Lactobacillus species isolated from the vagina: identification, hydrogen peroxide production and nonoxynol-9 resistance Contraception 2006;73:78-81. doi:10.1016/j.contraception.2005.06. 066.

27. Chun J, Lee J-H, Jung Y (2007) EzTaxon: a web-based tool for the identification of prokaryotes based on 16S ribosomal RNA gene sequences. Int J Syst Evol Microbiol 57:2259-2261. https://doi.org/10.1099/ijs.0.64915-0

28. Naser SM, Vancanneyt M, De Graef E, Devriese LA, Snauwaert C, Lefebvre K et al (2016) Enterococcus canintestini sp. nov., from faecal samples of healthy dogs:2177-2182. https://doi.org/10.1099/ijs.0.63752-0

29. Aslim B, Kilic E (2006) Some probiotic properties of vaginal lactobacilli isolated from healthy women. Jpn J Infect Dis 59:249-253

30. Botina SG, Sukhodolets W (2006) Speciation in bacteria: comparison of the $16 \mathrm{~S}$ rRNA gene for closely related Enterococcus species. 42:247-251. https:// doi.org/10.1134/S1022795406030033

31. Janda JM, Abbott SL (2007) MINIREVIEW 165 rRNA Gene sequencing for bacterial identification in the diagnostic laboratory: pluses, perils, and pitfalls. 45:2761-2764. https://doi.org/10.1128/JCM.01228-07

32. Law-Brown J, Meyers PR (2003) Enterococcus phoeniculicola sp. nov., a novel member of the enterococci isolated from the uropygial gland of the Red-billed Woodhoopoe, Phoeniculus purpureus. Int J Syst Evol Microbiol 53:683-685. https://doi.org/10.1099/ijs.0.02334-0

33. Fisher K, Phillips C (2009) The ecology, epidemiology and virulence of Enterococcus:1749-1757. https://doi.org/10.1099/mic.0.026385-0

34. Niemi RM, Ollinkangas T, Paulin L, Pavel S, Vandamme P, Karkman A et al (2016) Enterococcus rivorum sp. nov., from water of pristine brooks:21692173. https://doi.org/10.1099/ijs.0.038257-0

35. Naser SM, Vancanneyt M, De Graef E, Devriese LA, Snauwaert C, Lefebvre K et al (2005) Enterococcus canintestini sp. nov., from faecal samples of healthy dogs. Int J Syst Evol Microbiol 55:2177-2182. https://doi.org/10. 1099/ijs.0.63752-0

36. Tanasupawat S, Sukontasing S, Lee J (2016) Enterococcus thailandicus sp. nov., isolated from fermented sausage (' mum ') in Thailand:1630-1634. https://doi.org/10.1099/ijs.0.65535-0

37. Round $J$, O'Connell RM, Mazmanian SK (2010) Coordination of tolerogenic immune responses by the commensal microbiota. J Autoimmun 34. https:// doi.org/10.1016/j.jaut.2009.11.007

38. Mikami K, Kimura M, Takahashi H (2012) Influence of maternal Bifidobacteria on the development of gut Bifidobacteria in infants. Pharmaceuticals 5:629642. https://doi.org/10.3390/ph 5060629
39. Lin H-C, Su B-H, Chen A-C, Lin T-W, Tsai C-H, Yeh T-F et al (2005) Oral probiotics reduce the incidence and severity of necrotizing enterocolitis in very low birth weight infants. Pediatrics 115:1-4

40. Penders J, Thijs C, Vink C, Stelma FF, Snijders B, Kummeling I et al (2006) Factors influencing the composition of the intestinal microbiota in early infancy. Pediatrics 118:511-521

41. Saarela M, Crittenden R (2016) Gut bacteria and health foods - the European perspective gut bacteria and health foods - the European perspective. https://doi.org/10.1016/S0168-1605(02)00235-0

42. Belicova (2004) Synergic activity of selenium and probiotic bacterium Enterococcus faecium M-74 against selected mutagens in salmonella assay. Folia Microbiol (Praha) 49:301-305

43. Are A, Aronsson L, Wang S, Greicius G, Yuan KL, Gustafsson JÅ et al (2008) Enterococcus faecalis from newborn babies regulate endogenous PPARY activity and IL-10 levels in colonic epithelial cells. Proc Natl Acad Sci U S A. https://doi.org/10.1073/pnas.0711734105

44. Franz CMAP, Huch M, Abriouel H, Holzapfel W, Gálvez A (2011) Enterococci as probiotics and their implications in food safety. Int J Food Microbiol. https://doi.org/10.1016/j.jifoodmicro.2011.08.014

45. Al Atya AK, Drider-Hadiouche K, Ravallec R, Silvain A, Vachee A, Drider D (2015) Probiotic potential of Enterococcus faecalis strains isolated from meconium. Front Microbiol. https://doi.org/10.3389/fmicb.2015.00227

\section{Publisher's Note}

Springer Nature remains neutral with regard to jurisdictional claims in published maps and institutional affiliations.

\section{Submit your manuscript to a SpringerOpen ${ }^{\circ}$ journal and benefit from:}

- Convenient online submission

- Rigorous peer review

- Open access: articles freely available online

High visibility within the field

- Retaining the copyright to your article

Submit your next manuscript at $>$ springeropen.com 